\title{
LA INDUSTRIA DE LA CARNE COMO PAISAJE El lugar de los mataderos y mercados de hacienda en la ciudad
}

\author{
Nadia Jacob \\ Consejo Nacional de Investigaciones Científicas y Técnicas (CONICET) - Centro Universitario Rosario de Investigaciones \\ Urbanas y Regionales (CURDIUR). FAPyD, Universidad Nacional de Rosario, Argentina. \\ Directora: Dra. Arq. Isabel Martínez de San Vicente \\ Email: arquitecta.nadia.jacob@gmail.com
}

\section{RESUMEN}

El presente trabajo se propone avanzar en el estudio del paisaje ganadero haciendo foco en el lugar del mismo en la escala urbana. Partimos del supuesto de que la industria de la carne tuvo un rol fundamental en los procesos de transformación de las ciudades. Tal es así, que los establecimientos ganaderos pasaron de tener en sus orígenes un lugar marginal en la ciudad, a convertirse en importantes generadores de urbanidad e imaginarios culturales. En orden de confirmar estas presunciones, por un lado, revisamos la construcción conceptual de la industria como paisaje y como proyecto en la disciplina urbanística. Mientras que por otro lado, analizamos el proceso de configuración material y simbólica del paisaje ganadero urbano a partir de un análisis comparativo de un caso de estudio local, los mataderos y mercados de hacienda de la ciudad de Rosario (Santa Fe, Argentina) con un referente emblemático, La Villette (París, Francia).

Palabras Clave: paisaje industrial - ganadería - escala urbana - proyecto

\section{ABSTRACT}

The present work proposes to advance in the study of the livestock landscape focusing on the place of it on the urban scale. We assume that the meat industry played a fundamental role in the process of transforming cities. This is so that the cattle establishments went from having in its origins a marginal place in the city, to become important generators of urbanity and cultural imaginary. In order to confirm these assumptions, on the one hand, we review the conceptual construction of the industry as a landscape and as a project in urbanism. While on the other hand, we analyze the process of material and symbolic configuration of the urban livestock landscape from a comparative analysis of a local case study, slaughterhouses and meet markets of the city of Rosario (Santa Fe, Argentina), with an emblematic reference case, La Villette (Paris, France).

Key words: industrial landscape - cattle raising - urban scale- project 


\section{INTRODUCCIÓN}

El presente trabajo pretende contribuir en el avance de la tesis de investigación "El paisaje productivo de la pampa ganadera en su proceso de industrialización. Los bordes fluviales de las provincias de Santa Fe y Entre Ríos". La misma, tiene como objetivo principal producir conocimiento sobre el proceso de formación y transformación de este territorio ganadero argentino. Asimismo, no apunta a un análisis homogéneo del territorio acotado, sino que pretende un estudio de la temática en las distintas escalas en las que se manifiesta el paisaje ganadero. En este artículo hacemos foco en la escala urbana y el lugar de la industria ganadera en la misma. Para lo cual tomamos como principal caso de estudio el sur de la ciudad de Rosario, donde se instalaron sucesivos Mataderos Municipales y Mercados de Hacienda, así como también las industrias asociadas a esta actividad (curtiembres, graserías, etc.).

Para abordar el estudio de este paisaje productivo partimos del supuesto de que existen determinadas cualidades formales y estéticas constitutivas de los grandes artefactos manufactureros urbanos hacen que hoy podamos considerarlos como paisaje. En las disciplinas vinculadas con el proyecto de la ciudad y el territorio esta renovada idea de paisaje genera diversas aproximaciones y estrategias de acción buscando reactivar los paisajes afectados (Sabaté Bel, 2010). En relación a esto último, presumimos que en las intervenciones que asumen a los paisajes industriales como proyecto se introdujeron importantes innovaciones y transformaciones, tanto en las estrategias de acción como en la práctica proyectual. Por otro lado, en relación con nuestro específico objeto de estudio, planteamos que la industria de la carne tuvo un rol fundamental en los procesos de transformación de las ciudades. Tal es así que los establecimientos ganaderos, pese a tener en sus orígenes un lugar marginal en la ciudad, fueron importantes generadores de urbanidad y de imaginarios culturales. Como así también, en las últimas décadas del siglo XX, fueron el germen de numerosos proyectos urbanos.

En orden de avanzar en la argumentación de estas hipótesis, este trabajo tiene como objetivos principales: por un lado, revisar la construcción conceptual de la industria como paisaje y como proyecto de manera tal que nos permita reflexionar sobre la emergencia actual de los paisajes industriales en la disciplina urbanística. Por otro lado, describir el proceso de configuración material y simbólica del paisaje ganadero urbano a partir de un análisis comparativo del caso de estudio local con un referente emblemático (La Villette en París), y así identificar los rasgos distintivos que se convierten en insumo para la regeneración urbana desde la mirada del paisaje. Con estos propósitos, el diseño metodológico propuesto presenta un doble abordaje teórico/empírico de tipo cualitativo. Se revisan tanto las transformaciones físicas, como así también los proyectos que se plantearon para estos fragmentos urbanos donde se emplazó la industria de la carne. De la misma manera, se rastrean los imaginarios culturales asociados a este paisaje a partir de las imágenes y los debates difundidos en los medios de circulación masivos (diarios, revistas y postales).

\section{CONCEPCIONES RENOVADAS. LA EMERGENCIA DEL PAISAJE INDUSTRIAL.}

\subsection{La mirada paisajística}

Para poder reflexionar acerca del paisaje industrial encontramos necesario, en primer lugar, precisar qué es lo que entendemos por paisaje. En relación a este, adoptamos la posición que sostiene que el paisaje es tanto su forma como su significado. Desde este enfoque, el geógrafo español Martínez de Pisón (2006:1423) define a los paisajes como "la concreción formal de la realidad espacial, no solo sus vistas, sino su materialidad, las agrupaciones, organizaciones de elementos, su estructuración, relación y dinámica, evolución, historicidad, cambio". De todas maneras, este carácter integrador que se le adjudica al paisaje no implica que "todo" sea paisaje, sino que las cualidades formales se suman a las estéticas para darle valor a una determinada transformación del espacio. 
En relación a esto último, es interesante advertir que las actividades productivas fueron, desde la génesis misma de la idea de paisaje, las que guiaron el descubrimiento de los mismos. Como destaca Corboz (2004), en el Renacimiento era el campo antropizado el que se encontraba en el fondo de los cuadros y el que se instala en la mirada como un país amable. De la misma manera, el paso de "bello" a "sublime" apareció de la mano de la Revolución Industrial y con esta el mar y la montaña, antes temidos, se convirtieron en paisaje. Según Bodei (2011) este cambio en la forma de sentir e imaginar no repercutió solamente en la mirada estética sino que significó una transformación en el modo en que el hombre se posicionaba frente a la realidad. Ya no se constituye a si mismo midiéndose con Dios, sino con la naturaleza salvaje frente a la que pretende ser superior. Con esta misma lógica, el nacimiento del desierto, como lo llama Roger (2007), tiene lugar recién en el SXX cuando en el Sahara se descubren yacimientos petrolíferos.

A pesar de que los paisajes que se descubren son los que se quieren conquistar con fines productivos, el componente natural no deja de ser el preponderante. De todas maneras, "el paisaje no es naturaleza: es cultura proyectada en las montañas, en los océanos, en los bosques, en los volcanes y en los desiertos" (Bodei, 2011:24). En definitiva, el paisaje se piensa desde la ciudad moderna como una vista autónoma y, al mismo tiempo, externa a la ciudad. Será recién con los parques públicos del SXIX que el paisaje ingresa definitivamente a la ciudad. Sin embargo, este paisaje diseñado con criterios urbanísticos no deja de ser naturaleza artificial. Nos preguntamos entonces, ¿cuáles son los factores que influyeron para que en la actualidad hablemos de paisajes industriales?

\subsection{La industria como paisaje}

Para intentar dar respuesta al primero de los interrogantes que planteamos en la introducción de este trabajo es importante resaltar que en las últimas décadas del SXX se produjo una vuelta a escena del paisaje en las disciplinas arquitectónica y urbanística. Esta última, desde su concepción tradicional, no ha podido dar respuesta a las problemáticas contemporáneas. Nos referimos fundamentalmente a las consecuencias socio-espaciales de la globalización, entre las que podemos destacar la proliferación de "no lugares", el vaciado de tiempo, la aceleración de las transformaciones, los fenómenos de fragmentación y segregación social y espacial (Sabaté Bel, s.f.). En este contexto, el paisaje se instala como estrategia posible al enfrentar esta realidad desde su cualidad subjetiva.

En lo que respecta particularmente al paisaje industrial podemos decir que el principal motivo por el que comienza a percibirse como tal está también vinculado a las transformaciones que tienen lugar con el cambio del modelo económico mundial. Según Waldheim (2016), cada sistema de producción configura una organización espacial específica. Así, el paso de un modelo Fordista a uno Post-Fordista que comenzó a gestarse en la década de 1970 significó, por un lado, el abandono de los establecimientos industriales obsoletos de los centros urbanos. Mientras que por otro lado, generó la expulsión de las industrias más nocivas a territorios con una regulación más flexible. Ambos procesos son consecuencia de un "modelo espacial distributivo" en el que las distintas fases de producción de los bienes de consumo tienen lugar en locaciones remotas alrededor del planeta (Waldheim, 2016; Borja; Castells, 1997).

Asimismo, estas transformaciones en los espacios de la producción tienen impactos contradictorios en la forma en que los individuos perciben a los artefactos industriales. Por un lado, tanto las ruinas industriales de la ciudad como la proliferación de nuevos establecimientos en el territorio son entendidos como "parte del progreso y el bienestar de nuestra sociedad, como si fuera un hecho ineluctable, aún si nos domina la convicción de que, en general, poco placer puede obtenerse de su contemplación" (Aníbarro; Valdéz 2016:1). Mientras que en las antípodas, se instala la idea de que este modelo industrial produce lugares que no son el resultado de una progresiva construcción cultural local y que transforman radicalmente las cualidades materiales de los sitios en los que se emplazan.

De todas maneras, es esta percepción ambivalente la que se conjuga en la categoría estética que re significa a estos artefactos industriales. Como explican Aníbarro y Valdéz (2016), la dicotomía atracción/rechazo - fascinante/detestable 
se acerca a la de deleite/horror que caracteriza al sentimiento de "sublime" descripto por Burke. Sin embargo, como comentamos anteriormente, esta idea de lo sublime surgió para describir las sensaciones que generaba la naturaleza en el hombre moderno. En la actualidad, y en el contexto que venimos describiendo, la apreciación de una "naturaleza sublime" como la denomina Bodei (2011) es sustituida por la de "sublime artificial" que, como sostienen Aníbarro y Valdéz (2016), representa mejor el sentir ante las ruinas modernas de la industria. Podríamos decir, avanzando en esta idea, que la experiencia estética de la industria encarna los conflictos internos que atormentan hoy al hombre. Este ya no se conmueve ante el espectáculo de la naturaleza sino ante su propia obra, de la cual es moralmente responsable.

Asimismo, a pesar de que ambas actitudes contribuyan en la consideración estética de la industria, entendemos que es a partir de la segunda que surge definitivamente una mirada paisajística hacia esta. Como asevera Berque (2009:21), "nos preocupamos por el paisaje en la misma medida en que este se ve amenazado, lo mismo es válido para el medio ambiente". Fundamentalmente en las disciplinas vinculadas con el proyecto de la ciudad y el territorio esta realidad genera diversas aproximaciones y estrategias de acción buscando reactivar los paisajes afectados (Sabaté Bel, 2010). En esta dirección, los estudios de los paisajes del trabajo que se conciben como insumo de proyectos a diversas escalas, fluctúan entre los que ponen énfasis en revitalizar y proteger su patrimonio cultural, y los que hacen foco en recuperar las cualidades ecológicas del paisaje.

El primer grupo, retoma el concepto de paisaje cultural como una imagen vinculada a la identidad cultural de un territorio que Carl Sauer desarrolló a principios del SXX, y que luego es adoptado por la UNESCO (Organización de las Naciones Unidas para la Educación, la Ciencia y la Cultura) a fines del siglo, desde una preocupación más administrativa, preservadora y política, que académica u orientada al proyecto (Sabaté Bel, 2006). De todas formas, este organismo abrió el camino tanto a numerosas indagaciones académicas, como a convenios, regulaciones, planes y proyectos del paisaje que se traducen consecuentemente en: catálogos de paisajes; cartas de paisaje; proyectos de parques patrimoniales e itinerarios (Busquets; Cortina, 2009).

El segundo grupo, está integrado por los estudios que siguen la línea conceptual de la Arquitectura del Paisaje norteamericana, que en estos últimos años viene desarrollando la idea de un Landscape Urbanism. Desde este enfoque, los paisajes industriales en desuso se convierten en lugares de proyecto cuyo abordaje pretende vincular la dimensión cultural del paisaje con la ecología (Waldheim, 2006). A través de esta última se intenta entender la dinámica compleja del medio, adoptando también sus métodos y técnicas de descripción. Sin embargo, sus proyectos siguen apuntando mayoritariamente a la remediación de sitios deteriorados, tomando la forma de parques territoriales que se vinculan con espacios infraestructurales.

\subsection{Los paisajes industriales como proyecto}

En relación con las aproximaciones proyectuales que describimos en el apartado anterior, Aníbarro y Valdéz (2016) plantean una clasificación de los paisajes industriales que atiende a las posibilidades de acción que presentan los mismos. Con este criterio, el autor identifica al menos cinco tipos de paisajes: "paisajes de sustitución" (en los que desaparece el paisaje original y es sustituido por un artefacto tecnológico, como pueden ser represas y minas a cielo abierto); "paisajes de recuperación" (en los que se puede volver en cierto grado al estado original, como por ejemplo los yacimientos carboníferos); "paisajes de protección” (los que a pesar de no modificar la forma del territorio tienen un fuerte impacto contaminante, como ser las centrales térmicas y nucleares); "paisajes potenciales" (los que no dejan huellas materiales significativas y pueden adoptar formas que se adapten al entorno, entre estos se encuentran las instalaciones de producción de energías renovables como la solar o eólica) ; y los denominados "paisajes de agregación" (en los que al finalizar el ciclo productivo se reutilizan las instalaciones, como por ejemplo las estaciones ferroviarias o los depósitos de gas). 
Si vinculamos estos tipos de paisajes industriales con las transformaciones en los espacios de la producción PostFordista que relatamos previamente podemos decir que los paisajes de sustitución, recuperación, protección y los potenciales, representan claramente al modelo espacial distributivo. Mientras que por otro lado, los paisajes de agregación son el resultado de los procesos de desindustrialización de los centros urbanos, que deja a su paso establecimientos industriales obsoletos. Los primeros, tienen en común que su emplazamiento es en sitios comúnmente alejados de las urbanizaciones y con superficies que abarcan amplios territorios. Asimismo, estos se caracterizan por su doble condición de aculturales y extraterritoriales, realidad que genera importantes conflictos en el momento en que estas industrias de capitales globales se retiran en búsqueda de nuevos territorios que explotar. Esto se debe a que la comunidad local no se identifica con estos gigantes extranjeros, de los que ni siquiera participa en su construcción (frecuentemente de rápido montaje y mano de obra especializada). Como así también, la escasa participación de los estados nacionales en estos procesos, limitan las acciones que podrían revitalizar estos paisajes.

Los segundos, se distinguen fundamentalmente por sus cualidades simbólicas, ya que suelen ser las ruinas de industrias que tuvieron un rol importante en la configuración de los lugares en los que se emplazaron. Como así también son el resultado de prolongados procesos de tecnologización de determinado tipo de producción. Estos paisajes de agregación, como su nombre lo indica, se convierten en piezas estratégicas que posibilitan "unir una parte a un todo". Más aún si tenemos en cuenta que las industrias que tradicionalmente se encontraban en la ciudad ocupaban amplios espacios que, con el crecimiento acelerado de la urbanización, se volvieron clave para el desarrollo de la misma. Por otro lado, podríamos decir que los tipos de proyectos que se llevan adelante en estos espacios obsoletos, no solo representan "una nueva clase de espacio público" (Aníbarro; Valdéz 2016) sino que también son los que abren el camino a una nueva forma de proyectar el paisaje.

En el apartado anterior explicamos cuáles son los enfoques que actualmente guían las estrategias de acción en el paisaje. Sin embargo, para poder comprender este modo renovado de abordar las intervenciones en el paisaje entendemos que es necesario sintetizar cuáles son las innovaciones que se introducen en los diseños de estos paisajes industriales. Según Aníbarro y Valdéz (2016), en primer lugar, esta nueva generación de proyectos supera la estrategia general de rehabilitación de los edificios industriales para usos culturales o recreativos. Esto se logra planteando una indefinición de los usos que pueda absorber demandas futuras a partir de una reordenación de todo el conjunto, que incluye asimismo la recuperación de los espacios intermedios y los abiertos. Como así también, en estas intervenciones tienen un rol fundamental las medidas de remediación medioambiental debido a que en estos establecimientos los procesos productivos solían ser altamente contaminantes. Por último, el autor destaca la lectura por capas a modo de palimpsesto que propician estos proyectos en los que conviven elementos de distintas fases de la configuración del paisaje.

A estas innovaciones se le suman cambios en la práctica proyectual, en la que importan más los objetivos que persigue el proyecto que lograr una determinada forma final. Para lograr esto, la metodología de diseño se basa en los procesos que dejan el proyecto abierto a la contingencia y el cambio, tanto en lo que respecta al estrato natural como a las infraestructuras de los espacios de movilidad. Asimismo, se incorporan estrategias que acentúan las cualidades permanentes del paisaje ya que la idea de estas intervenciones no es reconstruir el pasado sino que se conviertan en lugares de la memoria, no solo del paisaje industrial sino de la estructura física que configuró parte de la ciudad. Por otro lado, a la lectura por capas con un criterio histórico que se refiera a la identidad del sitio, se le suma una estructuración por capas de los distintos modos de organización del proyecto, como por ejemplo, de los patrones de circulación en sus diversas escalas. En definitiva, todas estas estrategias abogan por la construcción de espacios públicos más complejos y dinámicos que solo son posibles si además de modificarse la práctica proyectual, se renuevan 
también los mecanismos de gestión. En este sentido, estas intervenciones son exitosas en la medida en que exista una multiplicidad de propietarios, concesionarios y agencias responsables de distintos aspectos de la financiación, la ejecución y el mantenimiento. (Berrizbeitia, 2007).

Si nos referimos específicamente a las transformaciones en el uso de técnicas e instrumentos, es importante resaltar que se desarrollan en el marco de equipos interdisciplinarios en los que cada profesional aporta sus conocimientos teóricos y técnicos. Esto permite la elaboración de detallados diagramas tanto de las etapas planteadas, como de las especies animales, los procesos de plantación de especies vegetales, los sistemas hidrológicos, y hasta de los programas posibles (Waldheim, 2006). Asimismo, el uso de estas técnicas de representación está asociado a un cambio en las prácticas visuales actuales que, en palabras de Allen (2009:149), cambian “del objeto al campo". Esto implica para la autora un giro comparable al paso del objeto analógico al campo digital, que se manifiesta en las simulaciones de cambio evolutivo por ordenador que se pueden aplicar en la práctica proyectual. En estas, no se registra la materia sino funciones, vectores y velocidades que representan a las fuerzas invisibles. De todas maneras, estas técnicas sumamente abstractas se combinan con otras más interpretativas y sensibles que se vinculan justamente con la mirada estética del paisaje. Así, como destaca sintéticamente Corner (2009:144), estas técnicas posibilitan “hacer enormes cambios de escala tanto en tiempo como en espacio, manejar mapas sinópticos junto con anotaciones privadas de carácter local, (...) introducir el espacio algebraico y digital del ordenador, y al mismo tiempo, estar jugando con pintura y arcilla".

\section{DE PAISAJE MARGINAL A GERMEN DE REGENERACIÓN URBANA}

\subsection{La industria de la carne como paisaje}

Para poder comprender el cambio en la percepción de los lugares de la ganadería urbana, los cuales pasan de pensarse como paisajes marginales a convertirse en paisajes de agregación, entendemos que es necesario reflexionar acerca de la importancia de esta industria en la configuración tanto física como simbólica de la ciudad. En relación al uso del espacio, ya desde el siglo XIX la industria de la carne comenzaba a distinguirse del resto de las industrias urbanas. Por un lado, a causa de la condición pública de sus establecimientos más significativos, mataderos y mercados, situación que emparenta a esta industria con instituciones estatales tales como los cementerios, cárceles y hospitales. A diferencia de estos organismos, los establecimientos ganaderos, antes privados, se transfieren al Estado debido a una necesidad de regular la oferta y demanda de un producto considerado básico en la alimentación. Como así también, para poder controlar una actividad que rápidamente se estaba convirtiendo en un problema para la ciudad.

Por otro lado, esta actividad tenía una significativa presencia material en la ciudad, diseminada en distintos tipos de establecimientos: por un lado, los dedicados a la producción de la carne y por otro, los que tenían como función principal el abastecimiento de este producto. Los primeros, fueron los saladeros que pronto se transformaron en mataderos y luego en frigoríficos, dedicados a la matanza y faena de los animales. Los mismos no solo ocupaban grandes superficies urbanas sino que su emplazamiento estaba condicionado por el acceso a abundantes cantidades de agua, la existencia de un lugar apto para arrojar los desperdicios y, fundamentalmente, por la presencia de conexiones viales terrestres (en la mayoría de los casos también fluviales) que permitieran el tránsito de las tropas de animales que llegaban desde los centros ganaderos rurales. Asimismo, alrededor de estos establecimientos se instalaban otros de menores dimensiones, que pertenecían a sus industrias asociadas (curtiembres, barracas, triperías, jabonerías, etc.). Entre los segundos, se encontraban los que comercializaban la carne, tanto los mercados de hacienda de escala regional, como las carnicerías a escala local.

A diferencia de otras industrias urbanas, a principios del siglo XIX la localización de esta fue objeto de numerosos debates públicos que derivaron en rigurosas normas relativas a su emplazamiento y funcionamiento. Los cuestionamientos estaban vinculados con una nueva mirada higienista de la ciencia médica que emparenta a esta industria con otras actividades que pasan de considerarse "naturales" de la vida urbana a observarse con alarma. De esta manera, "cuerpos enfermos, cadáveres, excrementos o animales de mataderos comienzan a ser vistos como parte 
no componente de la realidad cotidiana, en función no solamente de su existencia contagiosa, sino también de su condición de negativo social" (Aliata;Silvestri, 1988: 42-43). Esto tiene como resultado una nueva estructuración del espacio de la ganadería urbana, por un lado estos establecimientos son desplazados a los suburbios con el fin de ocultarlos como objetos urbanos. Por el otro, se busca concentrar las actividades en un solo sector de la ciudad y, en lo posible, en un solo edificio donde tuviera lugar tanto la preparación, muerte y descuartizado como la venta de los animales.
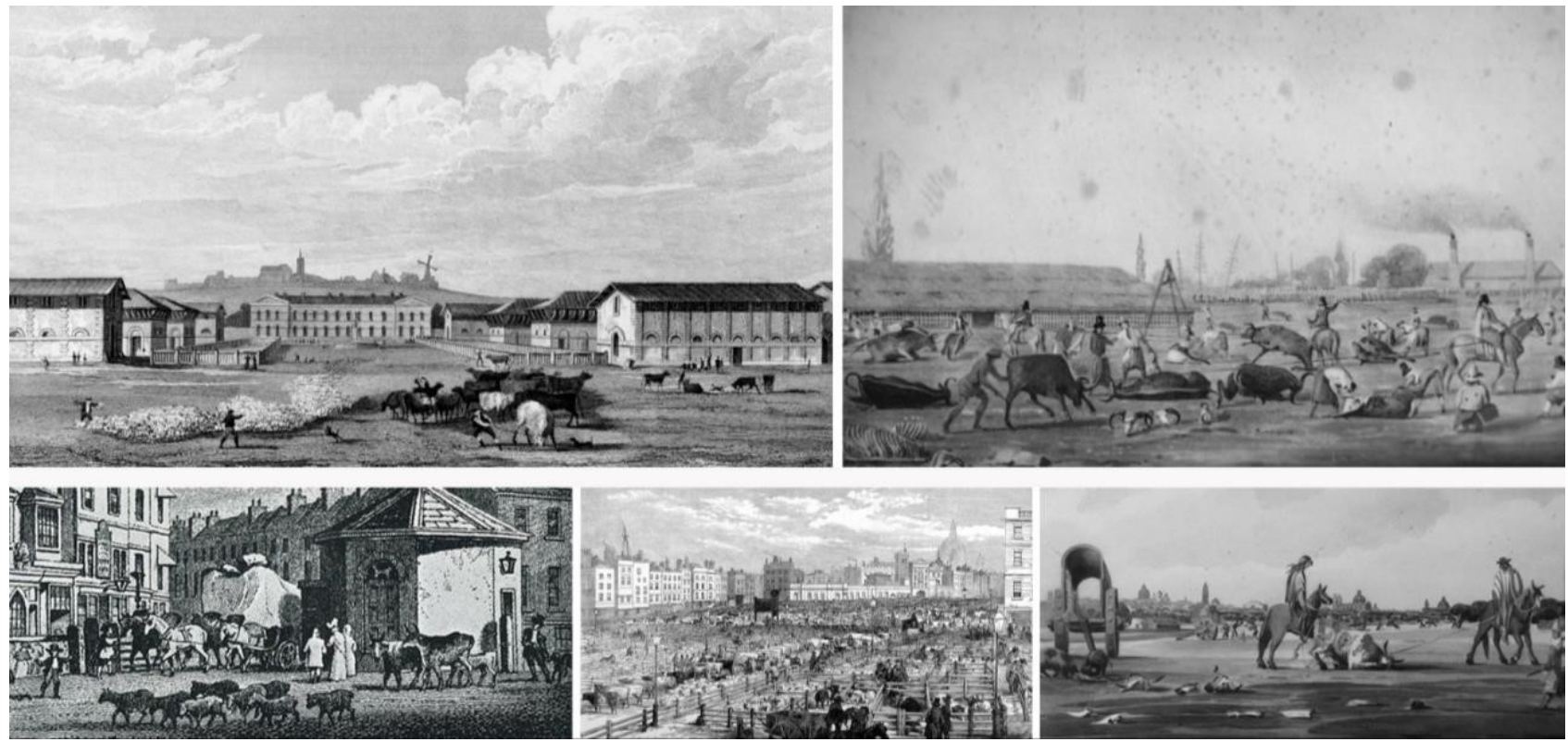

Fig. 01 El ganado inmerso en la ciudad del siglo XIX_Izquierda arriba: "Slaughtering House: Montmartre" (1831). Paris: Capital of the 19th. Century - Derecha arriba: "Matadero en 1829", Buenos Aires (acuarela de Carlos Pellegrini) - Izquierda abajo: "Detail of Islington toll gate", Londres (s.f.) - Centro abajo: "Last day of old Smithfield Market”, Londres en 1855 - Derecha abajo: "El matadero del SO de Buenos Aires", 1818 (acuarela de Emeric Essex Vidal). (Brown Digital Repository. Brown University - Monumenta iconográfica. Buenos Aires: Emecé (1985) https://ianeaustensworld.wordpress.com - http://www.victorianpicturelibrary.com Museo Histórico Nacional de Buenos Aires)

De todas maneras, estos intentos de separar físicamente la matanza del consumo, en definitiva, de separar el hombre del animal, no fueron posibles hasta avanzado el siglo XX. Fue necesario que confluyeran tres innovaciones tecnológicas: el ferrocarril, las comunicaciones por cable y la refrigeración, para que se acortaran las distancias espaciales y se transformaran las formas de desplazamiento de los animales en la ciudad (Robichaud; Steiner, 2010). Asimismo, entendemos el lugar de la calle como componente integrante de la industria de la carne fue determinante para que esta industria se instale en el imaginario cultural urbano. El pintoresco espectáculo de la matanza, habitual en este espacio público, se traslada a los mataderos y frigoríficos cuando se comienza a percibir como una exhibición horrible e insalubre. Sin embargo, la continuidad de la presencia de las tropas de ganado y de los carros abastecedores en las calles hace que las prácticas ganaderas permanezcan como imágenes de la cultura de la ciudad, arraigando la negatividad de su mirada

Lo singular de esta construcción simbólica es que al mismo tiempo que el paisaje de la industria de la carne se convierte en un paisaje marginal de la ciudad, comienza a ser visto como una representación de la Modernidad. Los mataderos y frigoríficos se transforman en dispositivos arquitectónicos higiénicos, racionales y civilizados, en los mismos se experimenta tanto con estructuras edilicias geométricamente racionalizadas como en nuevas formas de funcionalización del espacio. Tanto es así que ya desde principio del siglo XIX aparecen tratados de diseño que posicionan a los mataderos como un tipo arquitectónico moderno y, asimismo, como un problema de diseño legítimo. Ejemplo de esto es la 
participación de prestigiosos arquitectos en la evolución de este nuevo género de edificios, como es el caso de Tony Garnier quien en 1907 es contratado por el intendente de la ciudad de Lyon para proyectar un matadero moderno (Lee, 2008). De todas maneras, como analizaremos a continuación, la condición "moderna" de estos establecimientos estuvo arraigada al contexto de producción y al bagaje cultural de cada caso en particular.

\subsection{Distancias y proximidades. Los paisajes de la carne de La Villette parisina y el sur de Rosario}

En esta sección vamos a presentar una primera aproximación del análisis comparativo de dos casos de estudio que representan el paisaje de la industria de la carne en dos realidades, en principio disímiles, como son la latinoamericana y la europea. Asimismo, para este trabajo, nos centramos en el estudio del lugar en la ciudad de uno de los diversos tipos de establecimientos ganaderos urbanos. Nos referimos al Matadero Público y sus Mercados de Hacienda. En primer lugar tomamos un caso local, el de la ciudad de Rosario, en cuyo sector sur tiene lugar un proceso particular en el que los establecimientos ganaderos conviven, desde fines del siglo XIX hasta avanzado el XX, con la residencia burguesa y sus equipamientos recreativos. En segundo lugar, tomamos como caso paradigmático el de La Villette, dentro del $19^{\circ}$ distrito de París, sector anexado a la ciudad algunos años antes de la construcción del complejo industrial ganadero, donde ya existían fábricas y almacenes que vaticinaban el perfil productivo del área. Asimismo, consideramos que este ejemplo condensa dos atributos relevantes: por un lado, es un referente emblemático de la nueva generación de proyectos que describimos en el apartado anterior; por otro lado, es el caso que posiciona al paisaje de la industria de la carne como recurso a interpretar, proteger y proyectar.
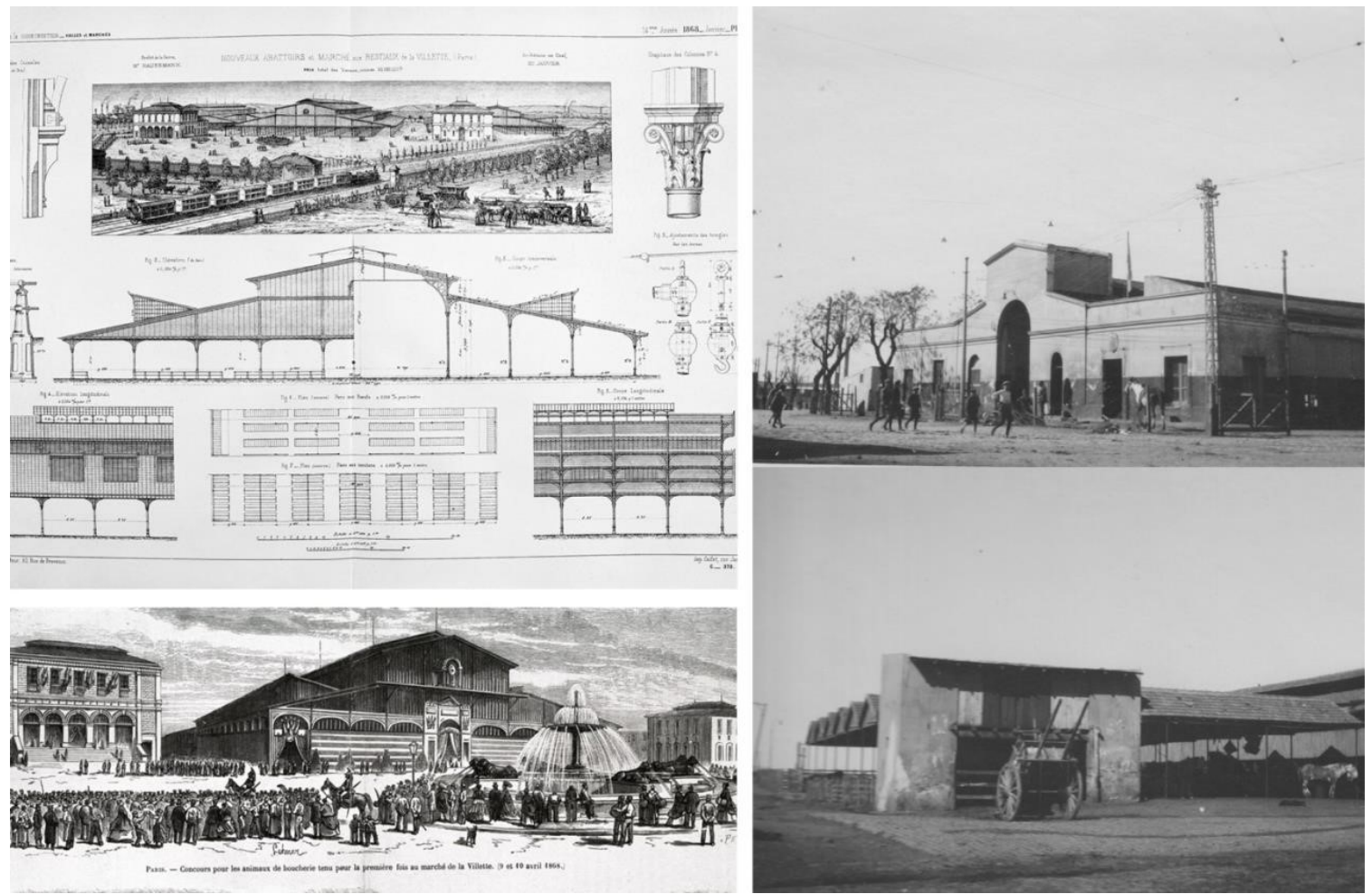

Fig. 02 Casos de estudio_Izquierda: La Villette__ Derecha: Matadero de Rosario (https://lavillette.com - Colección Piñero García. circa 1928. Archivo Fotográfico Museo de la Ciudad de Rosario)

La diferencia de escala entre ambas ciudades es significativa, para 1900 aproximadamente París contaba con más de 2.700.000 habitantes, mientras que en esta fecha en Rosario se censaban cerca de 112.500 habitantes. Asimismo, para ese momento La Villette de Paris faenaba 450 vacas por día (Douglas, 1907), unas 165.000 reses al año en un predio de 
54 ha, y el Matadero de Rosario un poco más de 73.000 vacunos (Municipalidad de Rosario, 1902) en una superficie de escasas 4 ha. Estos datos cuantitativos son significativos para advertir la importancia de la industria de la carne en el caso local, ya que comparado con una de las ciudades más importantes del siglo XIX cuya población es 25 veces mayor, su consumo de carne anual significaba poco menos de la mitad que el de la gran metrópoli europea. De la misma manera, estos números dan cuenta del fuerte impacto físico y cultural que representó el ganado en la ciudad de Rosario y sus alrededores. Tal es así, que en el Censo de población de 1910 se evidencia "la curiosa circunstancia de que (...) en el centro mismo de la ciudad viven hacinados en galpones, cantidad de vacas y caballos, ocupando un sitio que en verdad debería ser ocupado por construcciones aptas para el albergue de personas (...) que tienen que irse a vivir a los suburbios" (Municipalidad de Rosario, 1910).
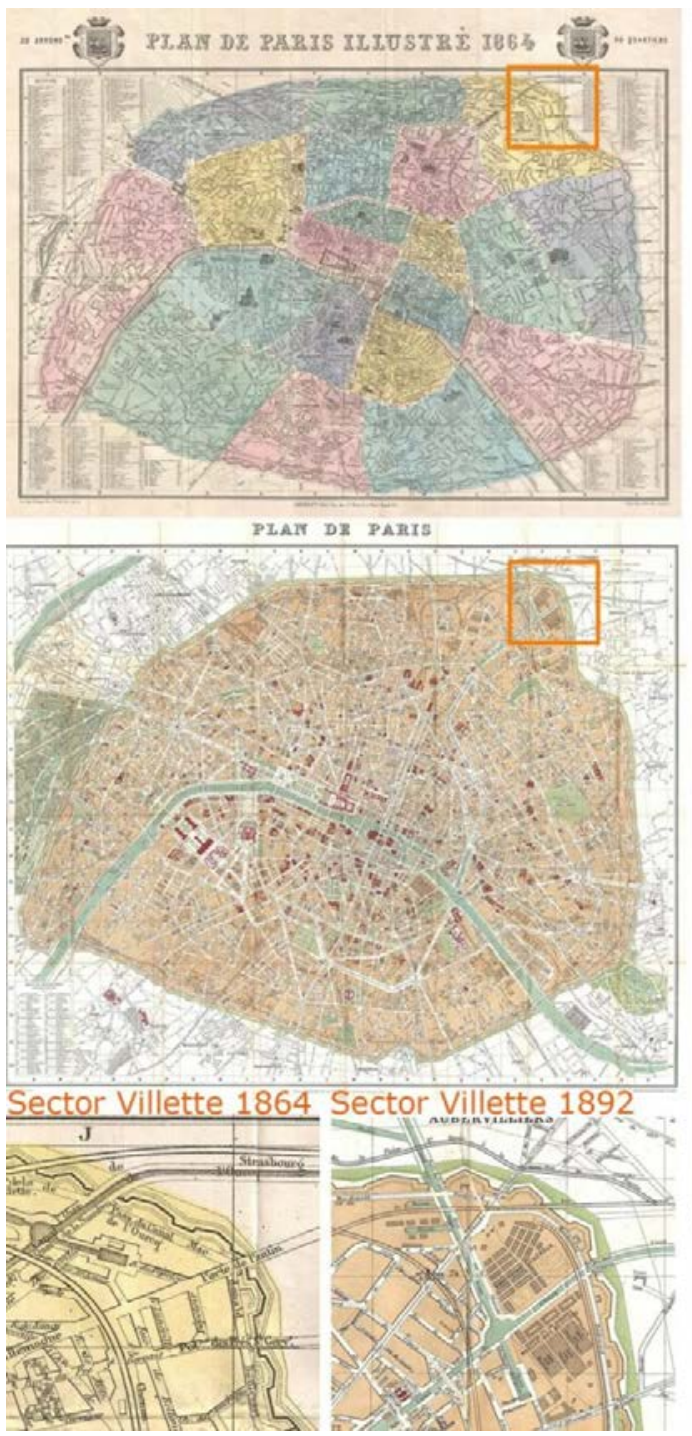

Fig. 03 El emplazamiento de los Mataderos en ambos casos de estudio_ Izquierda arriba: "Plan de Paris IIlustre” (1864) -

Izquierda abajo: "Plan de Paris" (1892) - Derecha arriba: "Plano de la ciudad del Rosario de Santa Fe"(Gabriel Carrasco, 1886) Derecha abajo: “Municipio de Rosario de Santa Fe” (Departamento Municipal de Obras Públicas, 1915).

(http://www.oldmapsofparis.com - http://www.victorianpicturelibrary.com - Colección Arch. Fotográfico Museo de la Ciudad de Rosario) 
En lo que respecta a la localización de estos establecimientos industriales, podemos decir que en ambos casos se confirman las afirmaciones hechas en el apartado anterior. Tanto en Paris como en Rosario los mataderos se ubican alejados de los centros consolidados y próximos a un curso de agua. El Matadero Municipal de Rosario abre sus puertas en 1876, en un sector del sur de la ciudad que todavía no había sido ocupado, en las inmediaciones del caudaloso río Paraná. De esta manera, se convierte en el primer germen de urbanidad del área, atrayendo la instalación de industrias afines a las que les proveía de materia prima, infraestructura de servicios y comunicaciones. Como así también, se localizan espontáneamente en sus alrededores las precarias viviendas de los trabajadores de estas industrias de la carne (Roldán, 2005). En el caso de La Villette (inaugurada en 1867), este equipamiento se emplaza en el límite NE de la antigua muralla medieval y sobre el canal de l'Ourcq, sector que ya tenía una estructura básica de ocupación. Asimismo, la ejecución del conjunto del Matadero y Mercado fue parte de un programa de reestructuración que el Prefecto Haussmann propone para la periferia degradada de Paris (Sáseta, 2012).

A partir de esta sintética introducción que describe el lugar que la industria de la carne tuvo en ambas ciudades, podemos decir que la condición "marginal”, de heterotropía como diría Foucault ${ }^{14}$, es un denominador común que caracteriza al paisaje de la carne más allá del contexto particular de cada caso. Así como también, le adjudica una valoración estética negativa que lo asocia con lo feo y el horror que se advierte rápidamente en la forma en que popularmente se denominaban estos sectores. En el caso de La Villette, el área era reconocida por el nombre que le habían dado los propios carniceros que allí trabajaban:

"la cité du sang" (ciudad de sangre). De la misma manera, los barrios del sur rosarinos donde se instaló esta industria se llamaban indistintamente en el uso común "tablada" o "mataderos". Asimismo, esta percepción negativa se difundía en los diarios y revistas de la época, tanto así que se convierte en el escenario de una de las pocas novelas que se escribieron sobre la ciudad titulada "Las colinas del hambre" (Wernicke, 2009), donde se describe crudamente el ambiente próximo a los establecimientos ganaderos.
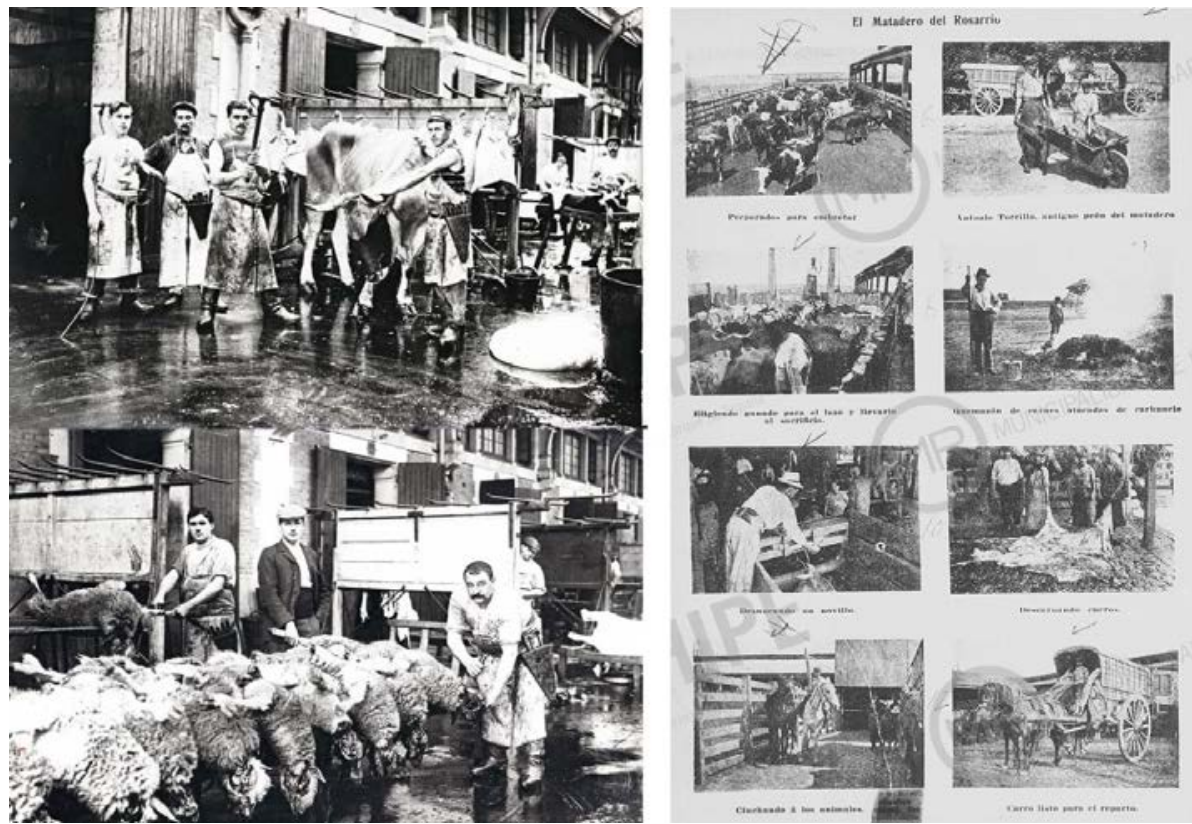

Fig. 04 La organización del espacio según los métodos de matanza. Izquierda: Carniceros trabajando en La Villette - Derecha: Secuencia de trabajo en el Matadero de Rosario (Fonds Pierre Haddad - Revista Monos y Monadas -1911-02-04)

\footnotetext{
${ }^{14}$ En su libro "Las palabras y las cosas" (1968), Foucault desarrolla la noción de heterotropía para referirse a los espacios que se contraponen a los utópicos. A diferencia de estos últimos, los espacios de las heterotropías son espacios reales que inquietan e incomodan, que son considerados un desvío con respecto a la norma.
} 
De todas maneras, la condición "moderna", que como explicamos en el apartado anterior también forma parte del imaginario que se construyó alrededor de esta industria, se manifiesta de forma distinta en estos dos casos. Por un lado, La Villette, desde su inauguración, fue considerada por los europeos como el mejor conjunto matadero del continente. Sin embargo, hoy se advierte que lo único moderno fue su localización, siguiendo las nuevas teorías de economía y medicalización del espacio. Según Claflin (2008:31), historiador cultural, este complejo parecía más una aglomeración de puestos carniceros particulares contenidos en células individuales que el reflejo de la evolución de un moderno matadero industrial. La estructura de sus tres pabellones de hierro se asemejaba al Champ de Mars de la Exposición Universal de Paris en 1867, por lo cual se percibía como una obra espectacular desde la calle. La realidad era que "la edificación representaba un diseño tradicional, hasta irracional" (...) visible en "los detalles operacionales, la distribución interior, los materiales de construcción, y la localización de los espacios de trabajo".

Por otro lado, el caso rosarino posee las particularidades que caracterizan a la "modernidad" de los mataderos argentinos tanto en su desarrollo tipológico como en sus vínculos con el territorio. Según Aliata y Silvestri (1988), este tipo edificatorio retoma algunos aspectos del modelo de los saladeros precedentes, como ser: la unidad espacial que favorece el control, la rapidez y eficacia de los procedimientos técnicos y la forma sencilla en que se disponían las construcciones. Así, en los establecimientos argentinos, los rasgos modernos están anclados a la tradición, contrariamente a lo que ocurre en Francia donde son justamente las prácticas más arraigadas las que conspiran para que este tipo edilicio no se renovara. Fundamentalmente nos referimos al método de trabajo de los carniceros quienes, concentrados en un único establecimiento, ejercían presión para que no se modifique su labor artesanal. Asimismo, a esto se sumaba el hábito de consumo de los franceses, quienes preferían el sabor de la "carne fresca", hecho que retrasó la adopción de sistemas de refrigeración en esta industria (Claflin, 2008).

\subsection{Transformaciones y conflictos. Los casos de estudio en el siglo XX}

Más allá de los numerosos conflictos sociales que ambos establecimientos generaron a partir del importante impacto ambiental producto de esta actividad ganadera urbana, sobre los que no haremos hincapié en esta presentación, existieron otros que estuvieron específicamente ligados a las transformaciones físicas que tuvieron lugar en estos espacios industriales. En este sentido, en el caso de La Villette la importante escala del proyecto original permitió que en el mismo terreno fuera posible llevar adelante todas las modificaciones edilicias necesarias, tanto para la aplicación de las nuevas tecnologías como las transformaciones que proponían las diversas teorías higienistas que fueron surgiendo a través de los años. Sin embargo, como vemos en la imagen a continuación, a mediados del siglo XX todavía no se habían llevado adelante transformaciones sustanciales en el conjunto. Es recién en torno a 1955 que se plantea una reconstrucción del conjunto y se lanza un concurso de anteproyectos. A partir del proyecto ganador se inicia el trabajo de demolición de gran parte de las antiguas edificaciones, el cual se frena en 1967 debido a falta de recursos.
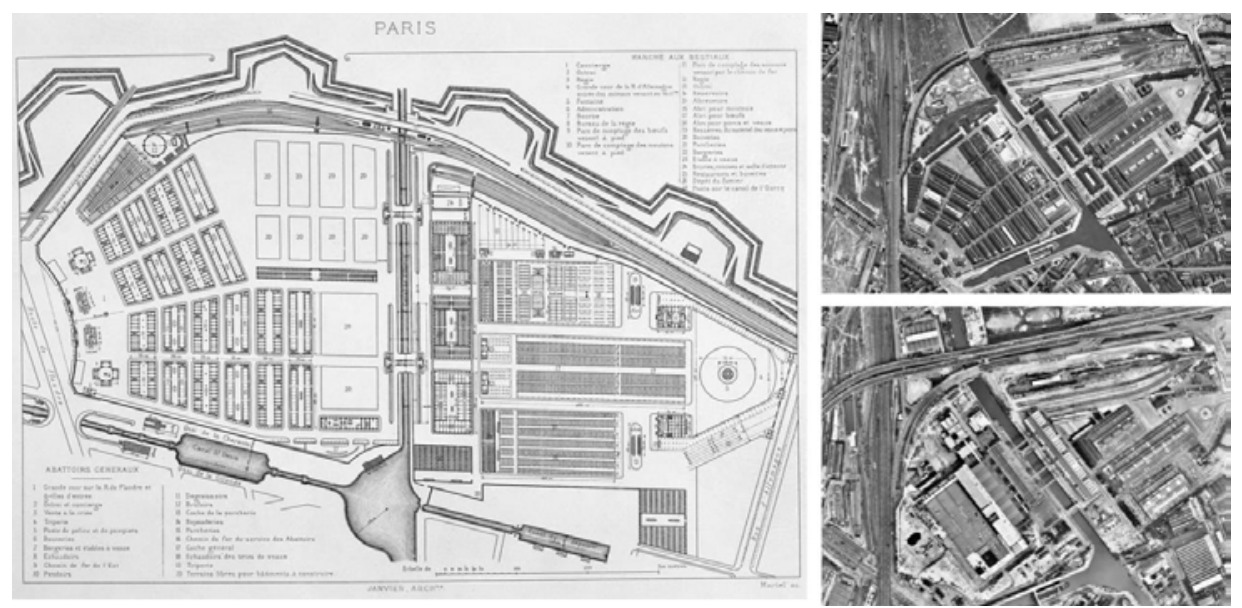

Fig. 05 Las tranformaciones de La Villette antes de su cierre_Izquierda: "Abattoirs Generaux et marche aux bestiaux_Plan General" (1868) - Derecha arriba: Foto aérea del complejo (1949) - Derecha abajo: Foto aérea del complejo (1970) (https://lavillette.com - 
Distinta fue la situación del Matadero rosarino, el cual a dos décadas de abrir sus puertas queda obsoleto, fundamentalmente porque no fue parte de una operación que repensaba la ciudad en su conjunto, como si fue el caso del Paris de Haussmann. Sumado a esto, el proyecto carecía de un racional cálculo de las necesidades futuras, tanto de un sistema de suministro de agua adecuado como de un apropiado sistema de transporte para llegada del ganado en pie. Pero fundamentalmente, no se había tenido en cuenta la reserva de terreno disponible para hacer las transformaciones edilicias necesarias. Esta situación generó numerosos debates acerca del destino de esta industria, los cuales devinieron en diversos proyectos, tanto de ampliación como de traslado, presentados al municipio por los empresarios más importantes de la ciudad. Estos vieron la oportunidad de hacerse cargo de la construcción del nuevo Matadero y Mercado de Hacienda a cambio de los cuantiosos beneficios económicos que les dejaría su concesión. Sin embargo, la presión de la opinión pública fue tan fuerte que todos los proyectos privados fueron rechazados (Garcilazo, 2012). Así, es recién en 1932, con la intervención de la Sociedad Rural, que se concreta la construcción de este conjunto, el cual no solo reemplaza al anterior sino que multiplica exponencialmente sus dimensiones (aproximadamente 30 ha) e incorpora el mercado en su interior.
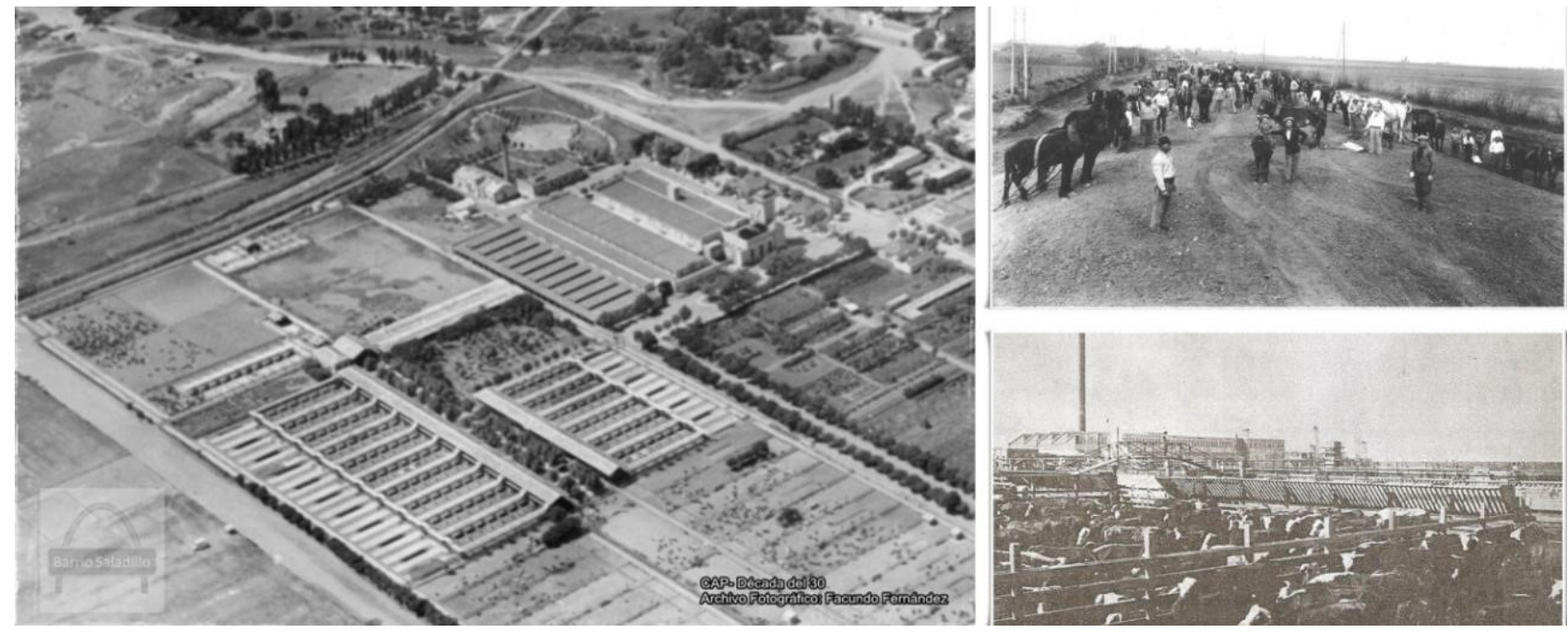

Fig. 06 Nuevo Matadero y Mercado de Hacienda de Rosario (www.barriosaladillo.com.ar)

En definitiva, aunque de maneras distintas, en ambos casos la industria de la carne configura un paisaje cultural propio alejado de los nuevos paradigmas de eficiencia e higiene que promulgaban los planificadores alemanes $y$ norteamericanos desde las últimas décadas del siglo XIX. Tal es así que, como expusimos anteriormente, La Villette recién en 1930 moderniza su equipamiento. De la misma manera que en esos años Rosario traslada, aún más al sur, sus establecimientos ganaderos con el objetivo de renovar las instalaciones. De todas maneras, en las últimas décadas del siglo XX estos establecimientos no solo estaban obsoletos, sino que se encontraban inmersos en áreas de la ciudad que habían dejado de ser periféricas. Después de casi 20 años de debates centrados en los costos económicos de las reformas, y con un concurso de anteproyectos para la reconstrucción del predio mediante, en 1974 La Villette cierra definitivamente sus puertas. Lo mismo ocurre con el conjunto rosarino, solo que 20 años más tarde, y debido fundamentalmente a los conflictos sociales que este generaba.

De todas maneras, en el caso rosarino, antes del traslado definitivo de estos establecimientos ganaderos fuera de la ciudad tiene lugar un proceso de transformación del predio y su entorno. El mismo comienza en la década de 1960 cuando se vende parte del Matadero a la Corporación Argentina de Productores de Carne y se cede una fracción de su propiedad para el funcionamiento del Vivero Municipal. Por otro lado, los sectores en los que antes funcionaban los corrales de hacienda son cedidos para la construcción de viviendas sociales debido al déficit habitacional del área. Sin embargo, los 
sucesivos proyectos de vivienda colectiva que se ejecutaron entre mediados de los 60's y principios de los 80's) fueron el resultado de una "sumatoria de acciones puntuales desestructuradas que fueron completando un importante vacío urbano" (Petronio-Salgado-Viu, 1991). A esta serie de cambios se suman los intentos de cerrar el predio ganadero que es promovido por reiteradas ordenanzas municipales que derogan su permiso de uso $\left(n^{\circ} 4.311 / 1987-n^{\circ} 4.387 / 1988-n^{\circ}\right.$ 5.121/1991). Como así también, por la difusión en los medios de comunicación de los peligros que significaba para la vida de los habitantes próximos al establecimiento. Sin embargo, estas iniciativas fueron frenadas por numerosas protestas de los trabajadores de la carne y por sucesivos pedidos de prórroga por parte de la Administración del Mercado (Ord. $\mathrm{n}^{\circ}$ $\left.4.669 / 1989-n^{\circ} 4.857 / 1990\right)$.
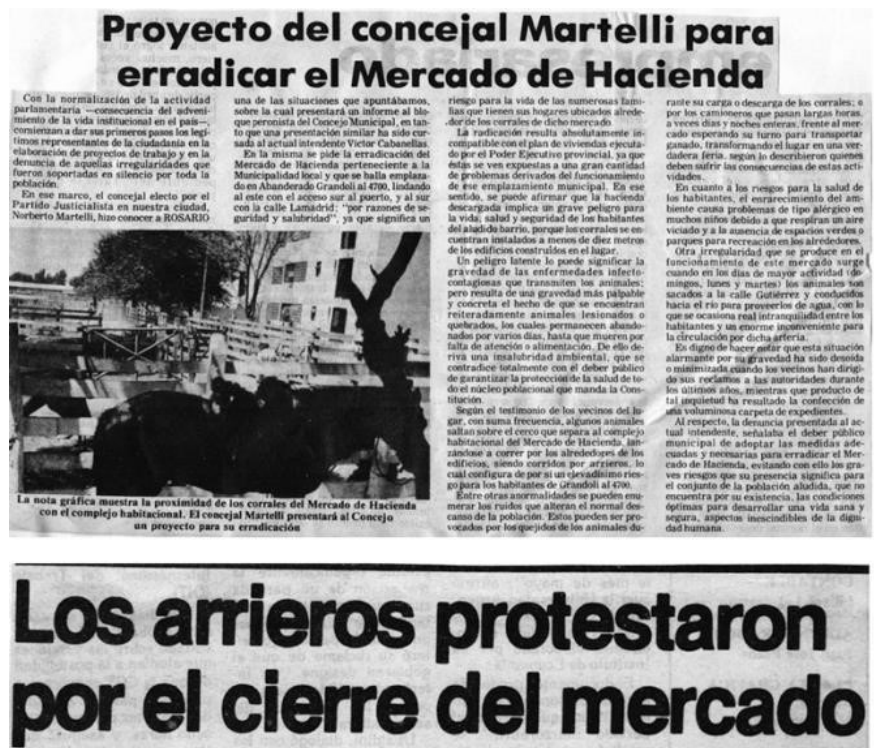
Se concentraron frente a la Municipalidad

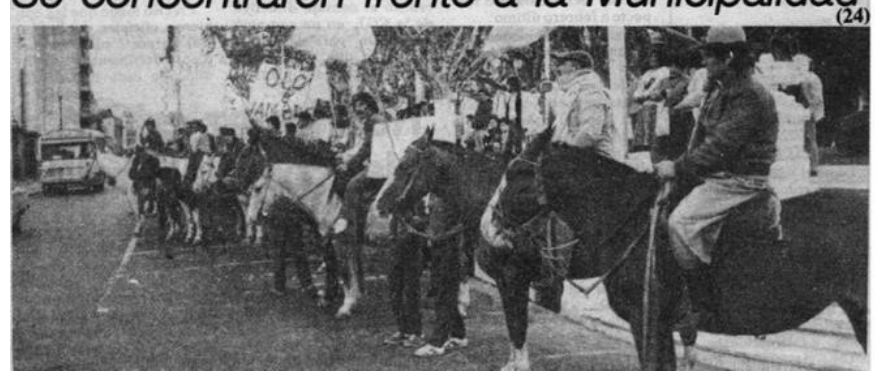

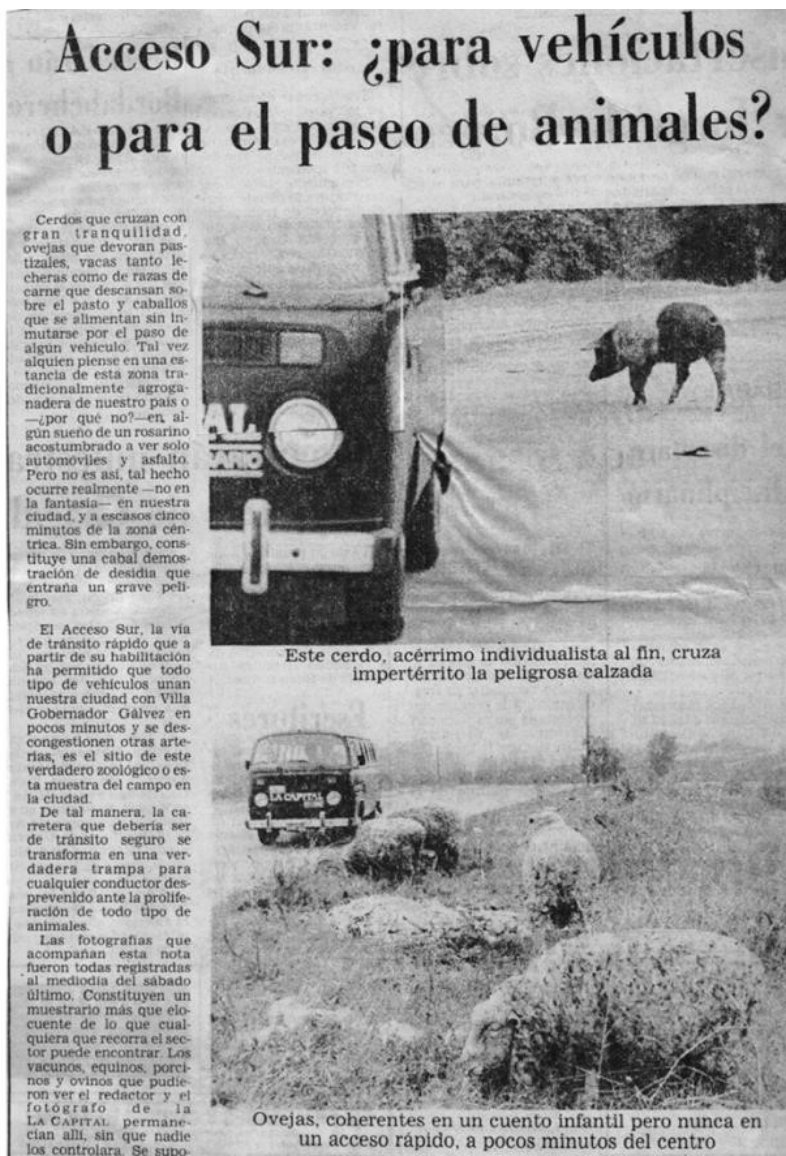

un acceso rápido, a pocos minutos del centro
un con

Fig. 07 Conflictos alrededor del cierre del Mercado de Hacienda rosarino (Diario "Rosario" 9-12-1983 - Diario "Rosario" 30-5-1985 Diario "La Capital" 30-6-1991)

\section{REFLEXIONES FINALES: PROYECTAR LOS PAISAJES DE LA CARNE}

En ambos casos, al poco tiempo que deja de funcionar la industria comienzan a formularse propuestas para transformar el sector. La diferencia con otros "paisajes de agregación" radica en que estos lugares del paisaje de la carne tenían asociados una percepción negativa que, como explicamos anteriormente, fue el resultado de un prolongado proceso de construcción cultural. En este sentido, entendemos que los proyectos que se plantearon en estos sectores tenían el desafío de rehabilitar predios abandonados y convertirlos en espacios públicos en los que se preservara la memoria del paisaje industrial. Pero además, se les presentaba el reto de ser el motor de transformación de un entorno degradado y por mucho tiempo negado por la ciudad. Particularmente en caso de Rosario en el que, como explicamos anteriormente, el predio del nuevo Matadero y Marcado de Hacienda fue perdiendo terrenos en el transcurso de la segunda mitad del siglo XX. La escala masiva de estos proyectos, sumada a la falta de equipamientos comunitarios y de espacios verdes demuestra claramente que el objetivo de estos proyectos no era recalificar el entorno. 
Como destacamos anteriormente, el Parc de La Villette de Bernard Tschumi, es considerado en la actualidad como un proyecto de paisaje emblemático ya que "abre el camino a grandes proyectos públicos en los que el paisaje es concebido como un medio complejo capaz de articular las relaciones entre la infraestructura urbana, los eventos públicos y el futuro indeterminado de los vastos sitios posindustriales" (Waldheim, 2016:15). En este sentido, los establecimientos del antiguo Matadero y Mercado de Haciendas, particularmente el Grande Halle y la inconclusa Sala de Subastas iniciada en la década de 1960, se presentaban como grandes espacios que permitían la variabilidad de usos. Así como también, diversos pabellones y algunos hitos que refieren a la historia de este paisaje forman parte del parque. Asimismo, este proyecto urbano tiene la particularidad de haberse desarrollado en el marco de un concurso en el que participaron 470 propuestas. El mismo, lanzado en 1982, plantea el desafío de diseñar un "Parque urbano para el siglo XXI". Lo interesante de este caso es que el segundo puesto del concurso, el proyecto de Rem Koolhaas, tuvo también una importante influencia como referente de una nueva forma de proyectar el paisaje. Su proyecto introduce la idea de la indeterminación programática a partir de un planteo en el que se propone un diseño en el que se yuxtaponen diversas "franjas de paisaje", reconociendo así las distintas capas que configuraron este paisaje a través de la historia.

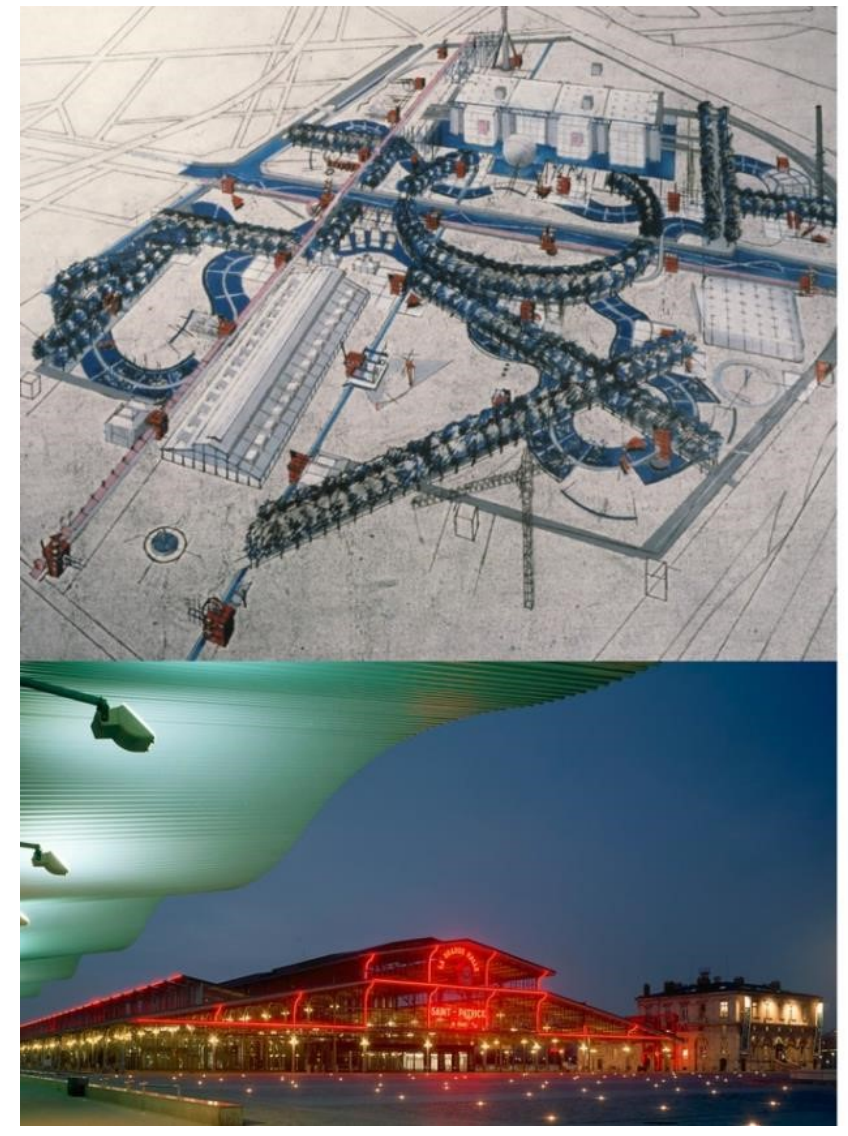

Fig. 08 Parc de La Villette - Bernard Tschumi (https://lavillette.com

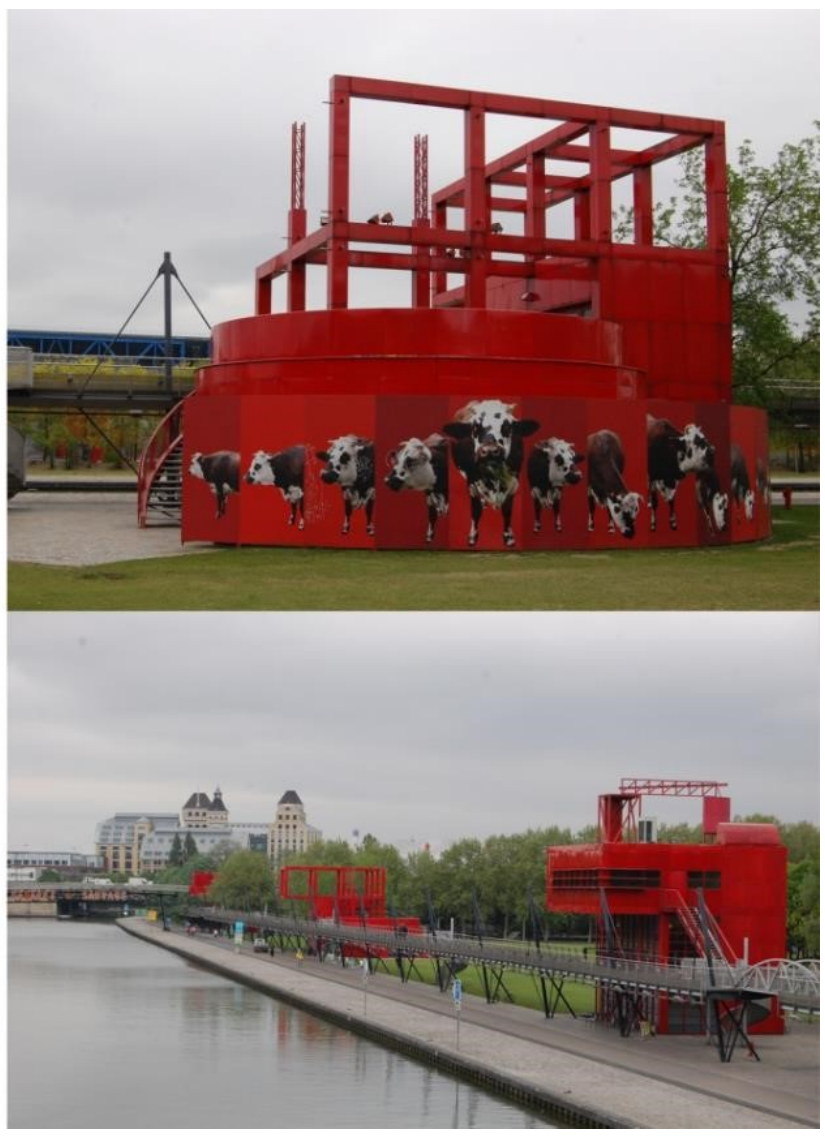

Fotos de la autora) 


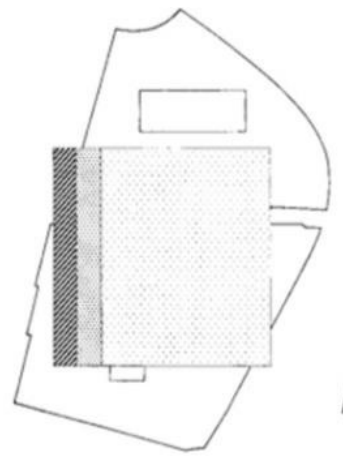

Initial hypothesis (scale: 1/20,000)

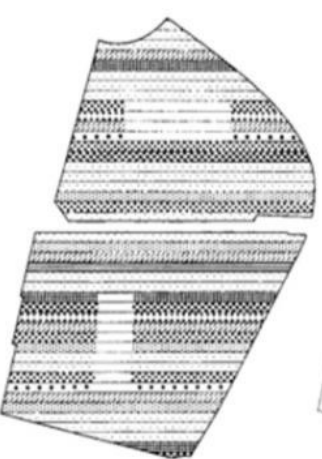

The strips

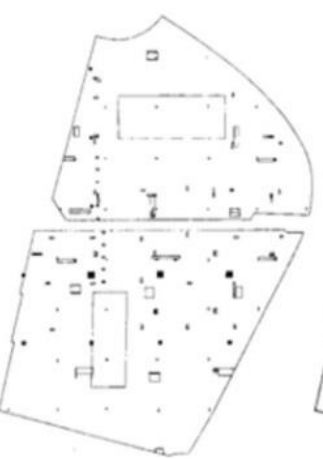

Point grids, or confetti

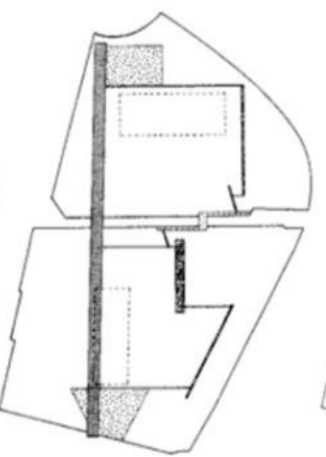

Access and circulation

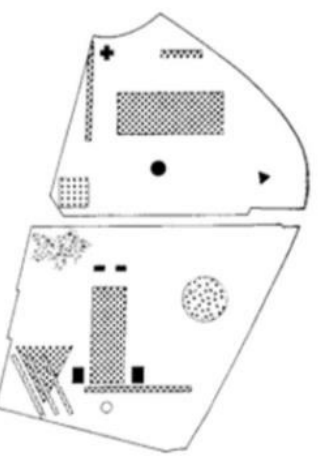

The final layer
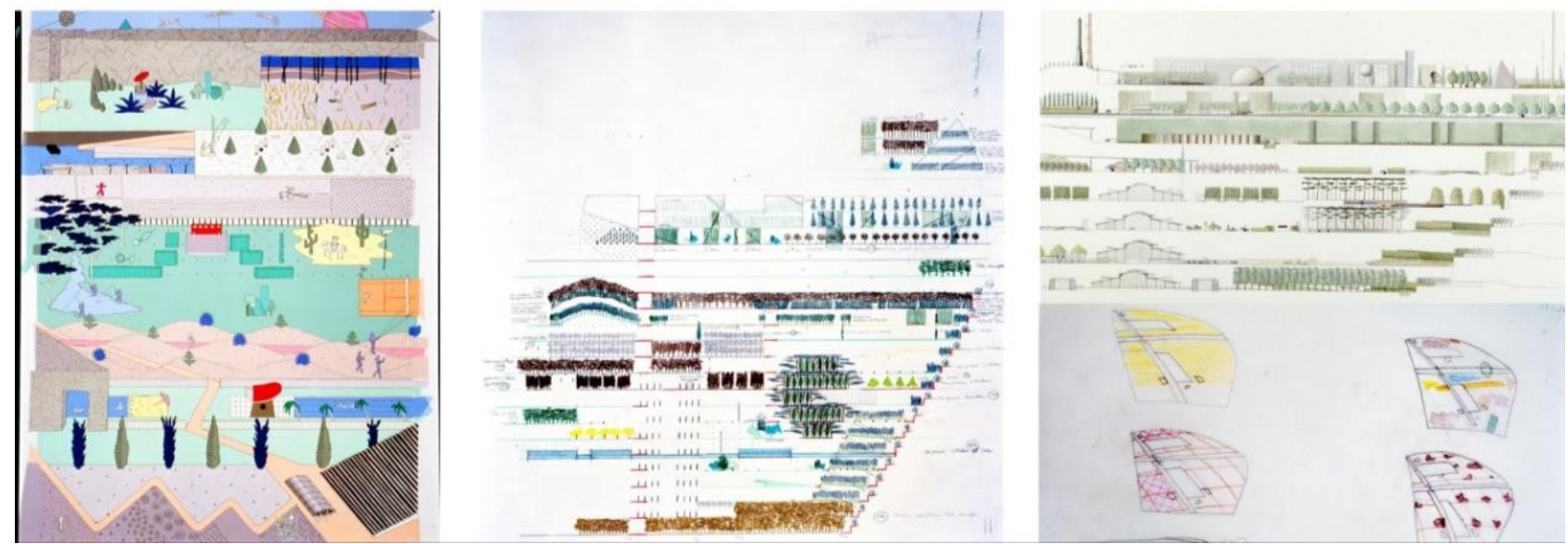

Fig. 09 Parc de La Villette - Proyecto de Rem Koolhaas (http://oma.eu)

A diferencia de este caso parisino, el proyecto que se inaugura en el sur de la ciudad de Rosario en 1991 no abre la posibilidad de debate y experimentación. El "Parque del Mercado" se desarrolla en las oficinas del municipio y se plantea más como un equipamiento deportivo que como un gran parque urbano. Su programa recreativo es cerrado y definitivo, y constaba básicamente con canchas para deportes diversos, una pileta e infraestructura y servicios para el área deportiva. Para estos últimos y para el funcionamiento del sector administrativo y de control sanitario se reutilizaron las naves principales de la obsoleta industria (Municipalidad de Rosario, 1995). De todas maneras, en este proyecto, las antiguas instalaciones del Matadero y Mercado son solo cáscaras en las que se emplazan nuevos usos. Como tampoco existen referencias al paisaje ganadero preexistente que permitan un anclaje del proyecto con la historia del proceso de formación de este sector de la ciudad. 


\section{La Intendencia adjudicó obra en el parque del Mercado}
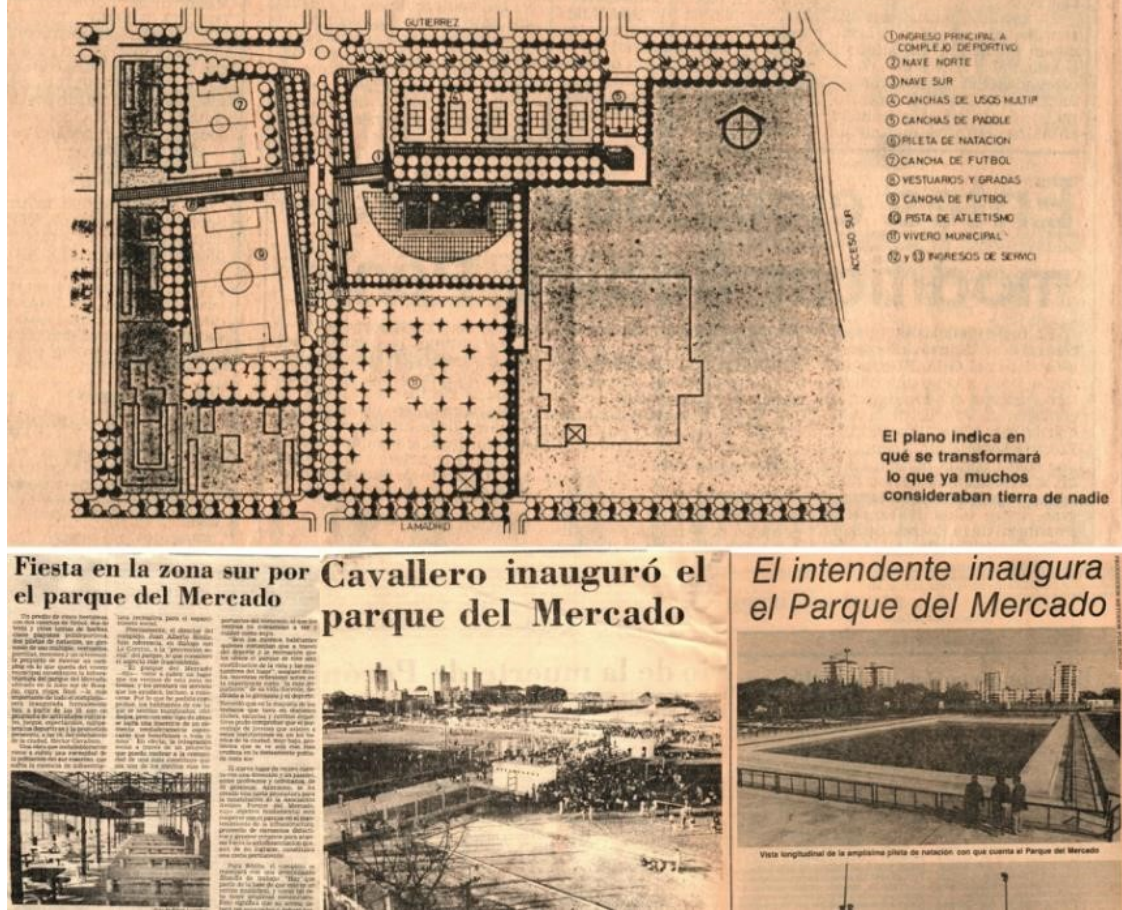

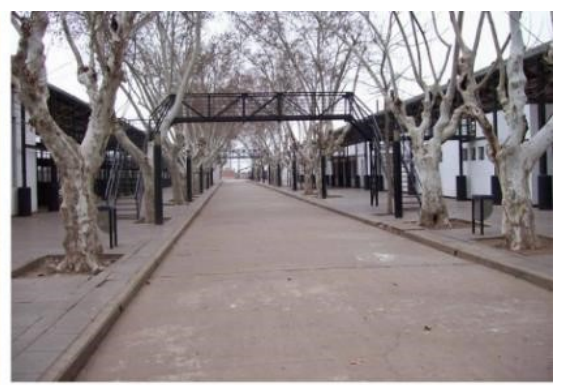
DMave sin

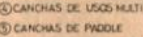
Dectu ce nutacio Qvestuatios r verions

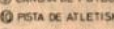
(9) rencesos as sem

El plano indica en que se transtormara consideraban tierra de nadie
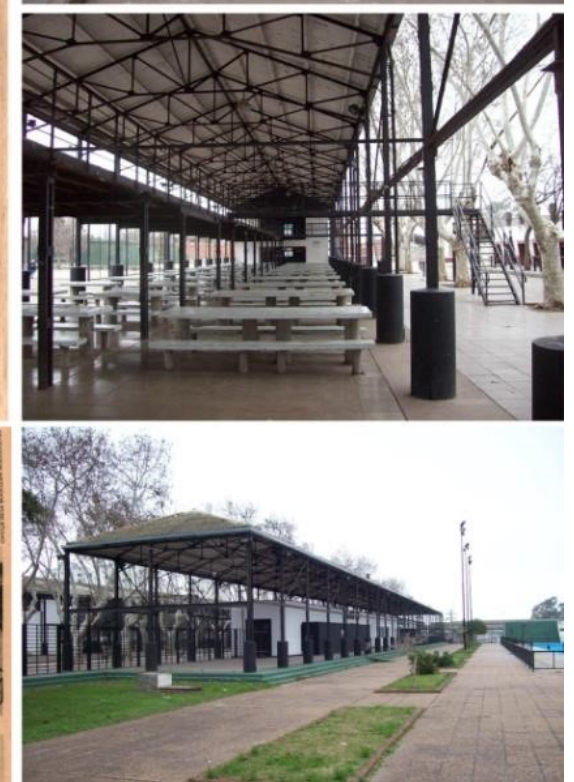

Fig. 10 Difusión del proyecto y de la inauguración del Parque del Mercado en Rosario y fotos de su estado actual (Diario “La Capital” 9-6-1991/ 23-5-1992/30-6-1991 / 23-5-1992 - Fotos de la autora)

En síntesis, más allá de las diferencias de escala y presupuesto que distancian a ambos proyectos, no existe en el caso local la voluntad política para repensar un sector de la ciudad en el que el paisaje de la carne continúa siendo percibido como marginal. Entendemos así que tanto el estudio de la configuración de este paisaje como el análisis de referentes internacionales pueden contribuir en el cambio de mirada necesario para que en un futuro próximo el paisaje se convierta en el eje de los proyectos de regeneración urbana de la planificación local. 


\section{BIBLIOGRAFÍA}

ANÍBARRO, M. Á. y VALDÉS, E. (2016) Fascinante y detestable. Artelización e integración de los paisajes industriales. Cuaderno de Notas (Madrid, Departamento de Composición Arquitectónica de la ETSAM / UPM), 17, 1-18.

ALIATA, F. y SILVESTRI, G. (1988). Continuidades y rupturas en la ciudad del ochocientos: el caso de los mataderos porteños. Anales del Instituto de Arte Americano (Buenos Aires: FADU/UBA), 26, 38-75.

ALLEN, S. (2009). Del Objeto al Campo: Condiciones de Campo en la Arquitectura y el Urbanismo. En I. ÁBALOS (Ed), Naturaleza y Artificio: El Ideal Pintoresco en la Arquitectura y el Paisajismo Contemporáneos. (148-170). Buenos Aires: Gustavo Gili.

BERQUE, A., (2009). El pensamiento paisajero. Madrid: Biblioteca Nueva.

BERRIZBEITIA, A., (2007). Re-Placing Process. En J. CZERNIAK y G. HARGREAVES (Eds), Large Parks (174-197). New York: Princeton Architectural Press.

BODEI, R. (2011). Paisajes sublimes. El hombre ante la naturaleza salvaje. Madrid: Siruela.

BORJA, J. y CASTELLS, M. (2000). Local y global. La gestión de las ciudades en la era de la información. México, D. F.: Santillana.

BUSQUETS FÁBREGAS, J. y CORTINA RAMOS, A. (coord.). (2009). Gestión del paisaje. Manual de protección, gestión y ordenación del paisaje. Barcelona: Ariel.

CLAFLIN, K. (2008). La Villette: City of blood (1867-1914). En P. Y. LEE (Ed.), Meat, Modernity, and the Rise of the Slaughterhouse (27-45). New England: UPNE.

CORBOZ, A., (2004). El Territorio como Palimpsesto. En A. M. RAMOS (Ed), Lo Urbano en 20 autores contemporáneos (15 - 36). Barcelona: UPC.

CORNER, J., (2009). Terra Fluxus. En I. ÁBALOS (Ed), Naturaleza y Artificio: El Ideal Pintoresco en la Arquitectura y el Paisajismo Contemporáneos (133-147). Barcelona: Gustavo Gili.

DOUGLAS, W., (1907). Douglas's encyclopaedia : a book of reference for bacon curers, bacon factory mangers, bacon agents, meat purveyors, meat inspectors, meat salesmen, abattoir superintendents ... and all other industries associatied with the meat, pork, provision and general food trades. Londres: The Firm.

FOUCAULT, M. (1968). Las palabras y las cosas: una arqueología de las ciencias humanas. Buenos Aires: Siglo XXI.

GARCILAZO, R. (2013). Un tema conflictivo: la propuesta de Juan Canals para la construcción de tabladas, mataderos y mercados de abasto, Rosario, 1889. Secuencia, 86, 113-135.

MARTÍNEZ DE PISÓN, E. (2006). Pensar el paisaje. En: MADERUELO, J. (Dir.), Paisaje y pensamiento (131-144). Madrid: ABADA.

MUNICIPALIDAD DE ROSARIO (1995) Rosario Arquitectura Pública. 1990-1995. Rosario: Secretaría de Planeamiento, Municipalidad de Rosario.

(1910). Tercer censo municipal de Rosario de Santa Fe. Rosario: Talleres de la República. 
(1902). Primer censo municipal de población con datos sobre la Ciudad del Rosario de Santa Fe (República Argentina). Buenos Aires: Talleres de Guillermo Kraft.

LEE, P. Y. (Ed.). (2008). Meat, Modernity, and the Rise of the Slaughterhouse. New England: UPNE.

PETRONIO, G.; SALGADO, M.; VIU, D. (1991). Vivienda financiada por el Estado en Rosario. 1928-1988. Rosario: FAPyDUNR.

ROBICHAUD, A. y STEINER, E. (2010). Trail of Blood: The Movement of San Francisco's Butchertown and the Spatial Transformation of Meat Production, 1849-1901. Spatial History Lab. Retrieved October. Stanford University., 8, 2012.

ROGER, A., (2007). Breve Tratado del paisaje. Madrid: Biblioteca Nueva.

ROLDÁN, D. (2005). Del ocio a la fábrica. Rosario: Prohistoria.

SABATÉ BEL, J. (2006).De la preservación del patrimonio a la ordenación del paisaje. En R. MATA y A. TARROJA (Coords.), El paisaje y la gestión del territorio (329-342). Barcelona: Disputació de Barcelona.

(s. f.): Paisajes culturales y proyecto territorial. Policopiado.

SABATÉ BEL, J. y BENITO DEL POZO, P. (2010). Paisajes culturales y proyecto territorial: un balance de treinta años de experiencia. Identidades: territorio, cultura, patrimonio, 2, 2-21.

SÁSETA, R. S. (2012). La sangre de las bestias: orígenes del matadero industrial. Análisis del Matadero Público de Reses de Sevilla, obra del arquitecto José Sáez y López (1895-1915). Función y estilo. Jornadas Andaluzas de Patrimonio Industrial y de la Obra Pública, Sevilla.

WALDHEIM, C., (2006). Landscape as Urbanism. En C. Waldheim (Ed), The Landscape Urbanism Reader (36-53). New York: Princeton Architectural Press.

(2016). The Landscape as Urbanism. New York: Princeton University Press.

WERNICKE, R. (2009). Las colinas del hambre. Rosario: Diario la Capital d 